\section{Research Square}

Preprints are preliminary reports that have not undergone peer review.

They should not be considered conclusive, used to inform clinical practice, or referenced by the media as validated information.

\title{
National implementation of in situ simulation training in Helicopter Emergency Medical Services: A multicenter study
}

Per P. Bredmose ( $\sim$ bredmose@hotmail.com)

Oslo Universitetssykehus https://orcid.org/0000-0002-5065-3590

\section{Jo Røislien}

Norwegian air ambulance

Doris Østergaard

Herlev Hospital

Stephen Sollid

Norwegian air ambulance

Original research

Keywords: prehospital, simulation, in situ, helicopter emergency service No conflicts of interest declared by any of the authors

Posted Date: September 9th, 2020

DOI: https://doi.org/10.21203/rs.3.rs-71574/v1

License: (c) (i) This work is licensed under a Creative Commons Attribution 4.0 International License. Read Full License 


\section{Abstract}

Introduction

Medical simulation is used in helicopter emergency services as a tool for training the crew. Using in situ simulation we aimed to evaluate the degree of implementation, factors for successful simulation and the crew's attitude towards this form for training.

Methods

A one year prospective study on simulation at all Norwegian helicopter emergency services bases and one search and rescue base. Local facilitators were educated and conducted simulations at their own discretion.

Results

All bases participated, but the number of simulations attempted at each base varied from 1 to 46 . Busier bases had a significantly higher number of aborted simulations. Regardless of base and number of attempted simulations, participating crews scored self-evaluated satisfaction with this form of training highly. The number of local facilitators and their travel distance to work seemed to make no difference to the number of attempted simulations.

Discussion

Our study reveals large differences in the number of attempted simulations between bases. Our findings suggest that the local facilitator is a key factor for successful implementation of simulation based training in helicopter emergency services.

\section{Introduction}

Medical simulation is an integral part of medical education, post graduate training and continuous professional development[1]. Several studies have shown simulation-based training has a positive effect on patient outcomes[2, 3].

In many countries, Helicopter Emergency Medical Services (HEMS) are responsible for the management of the most critical patients outside the hospital. Time critical interventions must be provided, and critical decisions made despite clinical uncertainty. The rapidity of transport by air can be beneficial to the patient but also creates a challenging environment with many hazards. Ensuring that care providers in HEMS have the right skills, experience and training to provide excellent care and take care of the patient's safety may require tailored training and skills maintenance[4]. Many emergency services have incorporated medical simulation as a core element in the training of personnel and crews in critical technical- and nontechnical skills[5-7]. However, simulation is resource demanding, both economically and logistically, and implementing effective training programs can be challenging in busy emergency services.

In a previous pilot study, we showed that in situ simulation is a feasible training concept for simulation training at the workplace during on-call hours for HEMS crews[8]. In that study, a simulation program was introduced at a busy HEMS base in Norway. The simulation training was shown to take up little time for the crews, and the response from the participating crews was generally very positive. To our knowledge, no other program for simulation training of on-call HEMS crews has been implemented on a national level in other systems. In the present study, we introduced a program of in situ simulation training through the entire Norwegian HEMS system.

The aim of this prospective study was to document the implementation of a national program of in situ on call simulation-based training for the crews in the national HEMS system in Norway. We also explored possible reasons for not attempting to start a training session, or why training was interrupted, along with the participants' and facilitators' satisfaction with the training.

\section{Material And Methods Norwegian HEMS system}

The Norwegian HEMS is a national service funded by the government. Commercial companies are contracted by the four regional health trusts in Norway to manage the flight operations. Medical staffing and medical responsibility for the service lies with the local health trust in which each base is located.

At the time of the project there were 11 HEMS bases run by two commercial companies with medical staffing from 11 local health trusts. Each base HEMS is staffed by a physician, a HEMS crew member (HCM) and a pilot. One base also includes an anaesthetic nurse in the crew. The physicians are all certified anaesthesiologists or within one year of being certified, and have experience in anesthesia, intensive care medicine, emergency medicine and advanced pain management. The HCMs are trained as emergency medical technicians, paramedics or nurses, and have additional training and experience in rescue techniques, including training in aviation theory, such that they are able to act as an assistant to the pilot. All 
physicians must also regularly perform in-hospital work. The pattern of shifts varies between bases: pilots and HCMs are generally on call 24 hours a day for one week, whereas physicians work for $24,48,72$ or 168 hours, depending on local work rotation.

All HEMS bases respond to primary medical and trauma missions and also perform interhospital transports and SAR missions. Some bases also perform transfers involving incubators, intra-aortic balloon pumps and extracorporeal membrane oxygenation (ECMO). The total number of missions and type of missions flown varies between the HEMS bases[9].

Six search and rescue SAR bases operated by the Royal Norwegian Air Force are also included in the Norwegian HEMS system. The medical staffing and equipment setup of the SAR helicopters is identical to the civilian HEMS, but the HCM is trained by the Air Force and the helicopter is additionally staffed with two pilots, a technician and a systems operator.

\section{Participants}

All 11 HEMS bases in Norway and one SAR base were invited to participate in the study. On each base, one or two experienced senior HEMS physicians were selected by the lead physician at each base to be trained as simulation facilitators. Before initiation of the study, these facilitators all completed the same simulation facilitator course together[10]. To ensure knowledge of local operating procedures, all facilitators only acted as facilitators for the in situ simulation training at the bases on which they normally worked. All facilitators received remuneration for simulation training outside their normal hours of work.

\section{Study design}

The study was conducted as a prospective multicenter study from October 31st 2014, to October 31st 2015. Simulation training was offered to the HEMS crews on call during daytime on days selected by the local facilitator on a convenience basis when it was possible for the facilitator to prepare and conduct the training. There were no requirements or expectations regarding the total number of sessions or their frequency during the study period. The simulation was presented as an optional learning and training opportunity for the crew, rather than as a compulsory task, because there was no previous tradition of simulation training as a crew. Before a training day, the facilitator would inform the on-call crew about upcoming training, and at his/her own discretion send the on-call crew relevant standard operational procedures (SOPs). All crew members were encouraged to participate in the training and the scenarios were designed to involve the physician, HCM and pilot. On the SAR base, the training was designed for the $\mathrm{HCM}$ and the physician primarily, but other crew members were invited to participate by the nature of SAR operations, the remaining four crew members of the six person SAR crew are less involved in medical care. We emphasized that the training should interfere with normal operations as little as possible.

\section{Scenarios and equipment}

The facilitators were encouraged to develop scenarios tailored to the mission profile of the base. The scenarios were designed to involve all members of the crew and could take place indoors, outdoors or both, although they were confined to the vicinity of the HEMS/SAR base to avoid disruption to crew readiness and delayed response to real missions. The facilitators were encouraged to have specific learning aims for each scenario and to ensure that no participants were exposed to the same scenario more than once. A total time consumption of one hour was regarded as optimal, but this could vary[8]. Facilitators were invited to share scenarios between bases.

The facilitators were encouraged to create packs of medical equipment specifically for training, similar in layout to those used at their base, and to use the helicopter's medical monitors to increase immersion in the scenarios. The facilitators were free to choose high- or low fidelity manikins or live actors for the simulations. Real-time physiological parameters were provided by either verbal information or via apps for smartphones and tablets that are commercially available. Additional diagnostic data could be made available if requested by the crews.

All simulation-based training sessions were planned to end with a structured debriefing which was performed using the PEARLS framework for debrief as described by Eppich, which is structured as; reaction, description, analysis, application/summary[11].

\section{Data collection}

Simulation duration was recorded by the facilitator in each case. The facilitator also noted if the simulation training was completed successfully and if not, the reason for interruption or cancellation. A simulation attempt was regarded as completed if simulation and debrief were completed, regardless of there were any interruptions. After each simulation the participating crew and the facilitator evaluated the degree of satisfaction with the simulation on a visual analog scale (VAS) from 0 to $100 \mathrm{~mm}$, where 0 represented completely unsatisfactory and 100 represented maximum satisfaction[12]. The facilitator's previous experience with medical simulation was noted, as was whether the facilitator lived close by or far away from the base (the latter defined by convenience as a travel distance of more than $30 \mathrm{~km}$ ). All data was recorded anonymously on a preconceived data collection sheet by the facilitator immediately after each attempted simulation training (Appendix A) and later entered anonymously into a digital database (Questback Essentials, Oslo, Norway).

\section{Statistical analysis}

Continuous data was summarized using median (quartiles), and categorical data as numbers (percentages). Comparisons of non-paired observations were done with Mann-Whitney's test. Association between the number of missions and simulation attempts at the bases was analyzed

Page 3/9 
using robust linear regression. Robust linear regression is a generalization of traditional linear regression that downplays the importance of outliers that might otherwise disproportionately affect regression coefficients. For the association between the number of missions and simulation success the analysis was weighted with respect to simulation attempts in a weighted robust linear regression. Data was analyzed using SPSS (IBM Corp. SPSS Statistics for Windows, Version 25, IBM Corporation, Armonk, NY, USA) and R 3.5.2[13].

\section{Results}

All 11 Norwegian HEMS bases and one SAR base were invited to participate in the study. One HEMS base planned to participate with remote facilitated simulation as none of the physicians could act as on-site facilitator. Due to technical difficulties this base opted out before initiation of the simulation training and we could only collect data from 10 of the 11 HEMS bases. All other invited bases participated.

A total of 176 simulation attempts were registered. Of these $65 \%(n=115)$ were completed. The number of attempted simulations among all participating bases is shown in Fig. 1a and the relationship between successful and unsuccessful simulations is illustrated in Fig. 1b. Table 1 shows the number of succesful and unseccessful simulations at each base as well as background information about the simulation training i.e. the number of facilitators; the time consumption; VAS scores for facilitators and crews' self-reported satisfaction with the simulation. The number of simulations initiated at each base ranged from 1 to 46 . Reasons for the failure to complete simulations are shown in Table 2.

Table 1

Distribution of background variablesrelated to thesimulation training at each of the 11 participating bases.

\begin{tabular}{|c|c|c|c|c|c|c|c|c|c|c|c|}
\hline \multirow[t]{2}{*}{ Base } & \multirow[t]{2}{*}{$\begin{array}{l}\text { Missions } \\
\text { per year }\end{array}$} & \multirow[t]{2}{*}{$\begin{array}{l}\text { Number of } \\
\text { facilitators }\end{array}$} & \multirow[t]{2}{*}{$\begin{array}{l}\text { Crew } \\
\text { size }\end{array}$} & \multirow[t]{2}{*}{$\begin{array}{l}\text { Attempted } \\
\text { simulations }\end{array}$} & \multirow[t]{2}{*}{$\begin{array}{l}\text { Successful } \\
\text { simulations } \\
(\%)\end{array}$} & \multicolumn{2}{|c|}{$\begin{array}{l}\text { Time consumption } \\
\text { Mean (SD) minutes }\end{array}$} & \multicolumn{2}{|c|}{$\begin{array}{l}\text { VAS score } \\
\text { Median (quartiles) }\end{array}$} & \multirow{2}{*}{$\begin{array}{l}\text { Facilitator } \\
\text { with } \\
\text { previous } \\
\text { experience }\end{array}$} & \multirow{2}{*}{$\begin{array}{l}\text { Facilitator } \\
\text { living } \\
\text { close to } \\
\text { base }\end{array}$} \\
\hline & & & & & & Facilitator & Crew & Facilitator & Crew & & \\
\hline$A$ & 2997 & 2 & 3 & 17 & $7(41 \%)$ & $98(51)$ & $\begin{array}{l}57 \\
(22)\end{array}$ & $\begin{array}{l}67[51- \\
79]\end{array}$ & $\begin{array}{l}\text { 87[83- } \\
90]\end{array}$ & $\mathrm{Y}$ & $\mathrm{Y}$ \\
\hline B & 1112 & 2 & 3 & 4 & $5(50 \%)$ & 166 (47) & $\begin{array}{l}86 \\
(18)\end{array}$ & $\begin{array}{l}80[54- \\
95]\end{array}$ & $\begin{array}{l}90[83- \\
95]\end{array}$ & $Y$ & $\mathrm{Y}$ \\
\hline C & 628 & 1 & 3 & 5 & 5 (100\%) & 99 (11) & $76(6)$ & $\begin{array}{l}86[82- \\
88]\end{array}$ & $\begin{array}{l}83[76- \\
98]\end{array}$ & $Y$ & $\mathrm{~N}$ \\
\hline D & 1783 & 1 & 3 & 5 & $3(60 \%)$ & $145(46)$ & $\begin{array}{l}59 \\
(15)\end{array}$ & $\begin{array}{l}79[75- \\
80]\end{array}$ & $\begin{array}{l}87[84- \\
96]\end{array}$ & $\mathrm{Y}$ & $\mathrm{Y}$ \\
\hline E & 1531 & 1 & 3 & 18 & $9(50 \%)$ & $101(20)$ & $\begin{array}{l}90 \\
(18)\end{array}$ & $\begin{array}{l}86[71- \\
88]\end{array}$ & $\begin{array}{l}93[80- \\
97]\end{array}$ & $\mathrm{N}$ & $Y$ \\
\hline $\mathrm{F}$ & 909 & 2 & 3 & 19 & $14(74 \%)$ & $118(55)$ & $\begin{array}{l}86 \\
(22)\end{array}$ & $\begin{array}{l}85[74- \\
90]\end{array}$ & $\begin{array}{l}85[79- \\
91]\end{array}$ & $\mathrm{N}$ & $Y$ \\
\hline G & 1805 & 1 & 3 & 14 & 10 (71\%) & 116 (32) & $\begin{array}{l}92 \\
(18)\end{array}$ & $\begin{array}{l}88[80- \\
92]\end{array}$ & $\begin{array}{l}90[86- \\
96]\end{array}$ & $\mathrm{Y}$ & $Y$ \\
\hline $\mathrm{H}$ & 875 & 1 & 3 & 1 & $0(0 \%)$ & $90(-)$ & $60(-)$ & $\begin{array}{l}86[86- \\
86]\end{array}$ & $\begin{array}{l}\text { 92[92- } \\
92]\end{array}$ & $\mathrm{N}$ & Y \\
\hline I & 833 & 1 & 3 & 20 & $14(70 \%)$ & 79 (15) & $57(9)$ & $\begin{array}{l}88[75- \\
92]\end{array}$ & $\begin{array}{l}88[82- \\
97]\end{array}$ & $\mathrm{N}$ & $\mathrm{N}$ \\
\hline$J$ & 696 & 2 & 3 & 23 & 18 (78\%) & $118(41)$ & $62(10)$ & $\begin{array}{l}74[65- \\
83]\end{array}$ & $\begin{array}{l}89[86- \\
91]\end{array}$ & $\mathrm{Y}$ & $\mathrm{N}$ \\
\hline $\mathrm{K}$ & 1061 & 2 & 4 & 46 & 31 (67\%) & 177 (64) & $\begin{array}{l}95 \\
(28)\end{array}$ & $\begin{array}{l}90[84- \\
90]\end{array}$ & $\begin{array}{l}\text { 91[87- } \\
93]\end{array}$ & $\mathrm{Y}$ & $\mathrm{Y}$ \\
\hline
\end{tabular}


Table 2

Number of successful and non successful simulations and reasons for failure to complete simulations.

\begin{tabular}{|c|c|c|c|}
\hline Outcome & Details & $\begin{array}{l}\text { Percentage ( } n=\text { actual } \\
\text { number) }\end{array}$ & $\begin{array}{l}\text { Causes of non-completed } \\
\text { simulations } \\
\text { (actual numbers) }\end{array}$ \\
\hline \multirow[t]{2}{*}{ Simulation completed } & Completed without interruption & $58.0 \%(n=102)$ & \\
\hline & Started, interrupted, but completed & $7.4 \%(n=13)$ & Priority mission: 13 \\
\hline \multirow[t]{4}{*}{$\begin{array}{l}\text { Simulation initiated, but not } \\
\text { completed }\end{array}$} & $\begin{array}{l}\text { Started, interrupted, but not } \\
\text { completed }\end{array}$ & $28.4 \%(n=50)$ & Acute mission: 42 \\
\hline & $\begin{array}{l}\text { Simulation conducted without } \\
\text { debrief }\end{array}$ & $3.4 \%(n=6)$ & \\
\hline & $\begin{array}{l}\text { Simulation conducted without } \\
\text { debrief }\end{array}$ & $2.8 \%(n=5)$ & Crew needs rest: 3 \\
\hline & $\begin{array}{l}\text { Simulation conducted without whole } \\
\text { crew }\end{array}$ & $2.8 \%(n=5)$ & $\begin{array}{l}\text { Some or all crewmembers not } \\
\text { motivated: } 4\end{array}$ \\
\hline
\end{tabular}

The number of simulation attempts was not associated with the total number of missions at the base (Fig. $2 \mathrm{a})-0.001$ (95\% $\mathrm{Cl}-0.010$ to, 0.009$), \mathrm{p}=$ 0.878 , while the number of completed simulations was significantly lower for the busier bases (Fig. $2 b)-0.017(95 \% \mathrm{Cl}-0.027$ to -0.006$), p=0.013$. Figures $2 a$ and $2 b$ show the association between number of missions and number of simulations. A statistically significant difference $(p=0.01)$ in the number of simulation attempts was seen between bases with one facilitator, and those with two facilitators: bases with only one facilitator had a median of $8(5 ; 16)$ simulation attempts as compared to $21(18 ; 28)$ for bases with two or more facilitators.

\section{Discussion}

In this study we found variations in the success of implementing in situ simulation for on-call crews in the 11 HEMS bases of the Norwegian air ambulance system and one SAR base. The workload of the bases, expressed through the total number of yearly missions, had no impact on the number of attempted simulations. However, bases with a low workload did manage to complete the simulations successfully significantly more often. The number of facilitators at each base positively impacted the number of simulations attempted. Their travel distance to the base did not seem to but this was not tested for significance due to the low number of simulations on some bases. Participating crews universally reported high levels of satisfaction with the simulation training with little variation between the bases.

More than half $(58 \%)$ of the simulations were completed without interruption. Most interruptions were due to acute missions. Only a few cancellations were due to crews' lack of motivation. This is in agreement with the crews' positive evaluation of the training.

The number of successfully completed simulations seems to be closely linked to the workload, (defined by number of yearly missions at the base). Bases with a low workload were able to complete simulation exercises more often than simulations started at high workload bases. This makes sense, as a low workload base has a lower risk of being interrupted once a simulation session has started.

One of the bases attempted to run 46 simulations over the one-year course of the trial, which corresponds to 1 simulation/week, if training is not planned for the busiest weeks of the year. It therefor seems feasible to arrange for weekly simulations. The other bases had lower number of attempted simulations, mostly less than half of the aforementioned base which indicate that the implementation was difficult. Few studies have investigated barriers to implementing simulation training but a study on the implementation of simulation training in surgery pointed at costs, practicality and motivational factors as main barriers to implement their concept[14].

Our study did not document implementation barriers, but we can from interpreting our data exclude some of the barriers proposed by Hosny et al from our project, whereas other are more likely to have played a role.

With the setup we chose in our project, with low fidelity and simple mannequins, we kept the cost of the training to a minimum. The only factual cost that our project generated was the financial compensation for the facilitators. By involving as few facilitators as possible this cost was however kept to a minimum.

Practicality was also maintained since training was tailored to the workload of the crews and the facilitator prepared everything before and after the simulation to minimize the additional workload for the crew.

The impact of motivational factors is more difficult to evaluate in our data material.

It might e.g. be important for leaders to promote and prioritize the simulation. Leadership approved the project but were not involved during the implementation period. We speculate that more support and encouragement of facilitators might have increased the number of attempted 
simulations. Different levels of support from leaders throughout the project might explain some of the variations between bases.

Since the attempted simulations are tightly coupled with the facilitators initiating them, the internal motivation and the work capacity of the facilitator may also play a role.

In our study we attempted to provide each base with equal resources. The facilitators were given the same training and tools to run the simulation program. We tried to avoid imposing a rigid framework onto the program which might stifle its adaptation to the local context and learning needs. For example, the facilitators could choose the level of fidelity, the day of the week and the content of the simulations. Nevertheless, there were significant differences between the bases in how successful they were in initiating and completing simulation training.

Tariq et al have previously described the importance of the follow up and supervision of facilitators being critical to successful in situ training at London HEMS[15]. They recognize the complexity of the facilitators' role and the need for education and feedback to facilitators.

We had no impact on the selection of facilitators on each base, and therefore were unaware of their motivations or previous experience. The facilitators received financial compensation for each simulation attempted, and this may have provided an extrinsic motivation for organizing simulations.

Although cautious in our interpretation we accept that training of facilitators, concept of the training and follow up of the facilitators throughout the project may have influenced the overall number of attempted simulations. We are less convinced that this also explains the variance in the number of simulations attempted at different bases: in this context it seems more likely that other external factors (general workload, competing commitments) or internal factors (local enthusiasm for the simulation training, interpersonal dynamics) played a role. This however remains only a speculation since our data did not record the motivations of the facilitator. During the study period, there was no follow-up of the facilitators or the achieved numbers of simulations on each base. Others have shown that motivation and encouragement of the facilitator is an important factor for the successful implementation of in situ simulation in emergency departments[16]. It is plausible that a monthly follow-up from the project coordinator, might have motivated some facilitators to run more simulations. The decreasing number of total simulations per month on all bases throughout the study period suggests that maintaining a program of simulation training over a period of time is likely to require ongoing support (Fig. 1a). Future and similar projects should therefore focus on removing barriers to successful completion of training and keeping the spirit alive among the facilitators.

Some facilitators lived closer to the base than others. We saw no consistency in whether this would have an impact on the number of attempted simulations. For future studies it would be of importance to explore whether this has an impact on either the crews' motivation for simulation or for the facilitators' willingness to wait for the crew to be available. There may be novel solutions to overcome these challenges: we know that some facilitators living far away from the base opportunistically used crew changeover-time for simulation (e.g. when the facilitator was going either on- or off-call) in order to minimize travel time.

The facilitators were free to deliver training as often as they wanted. However, we speculate that it might have been helpful for the facilitators to have regular and frequent contact with either other facilitators or the leaders of the project. In this way, encouragement and support could be given.

In our study we allowed each base to have one or two facilitators and we know that bases with two facilitators were able to attempt more simulations than bases with only one facilitator. The redundancy of having two facilitators may improve the ability to initiate simulations, and the facilitators may be able to motivate and support one another. Following completion of the study we became aware that some facilitators were unable to conduct simulation training due to long term sick leave. This was not recorded during the study, so we cannot know how this influenced the frequency of simulations, but it emphasizes the central role of the facilitator in the simulation program. Although not supported by this study, we pragmatically suggest that making at least two facilitators available at each base reduces the vulnerability of a simulation program and increases its chances of success. The participating crews at all bases reported high satisfaction scores in their evaluations of the simulation training (Table 1 ). This is in accordance with findings in a previous pilot study[8].

Discussion of methods used

In this study participation was voluntary: if training were compulsory more simulations might have occurred. Following the group training course, facilitators operated as individuals with no formal follow up or collaboration between the bases. To our knowledge facilitators did not share any scenarios or experiences between bases. Potentially, such collaboration might have improved the simulations and supported the facilitators, enabling them to collaborate on solving problems that they encountered. All facilitators were encouraged to adapt the training to their local SOPs and to create training packs that mimicked the actual equipment setup on the base, to increase the realism and appropriateness of the training. However, this did create more work for the individual facilitator, especially in the initial set-up phase.

Future perspectives

Often simulation training was not completed due to interfering missions for the on-call HEMS crews. It is a waste of human resources for a facilitator to prepare the training and attend the base without being able to complete the simulation. Also, this experience might demotivate the facilitator. As an alternative, in this circumstance it might be better for the facilitator to join the on-call crew and observe the live mission, and then conduct a structured debrief upon completion. Such observed practice is described positively by others[17]. 


\section{Conclusion}

We found that it is possible to implement in situ simulation training on a national level on HEMS bases with a high degree of satisfaction among the participating crews. Although all participating HEMS bases were offered an almost identical training and compensation for facilitators, we found differences in the number of attempted simulations. The proportion of simulations that were conducted successfully were related to the number of missions on each base.

\section{Declarations}

\section{Ethics approval and consent to participate}

Crews participated in the simulation training on a voluntary basis. Responding to the questionnaire was also voluntary and anonymous. Individuals could withdraw their responses to the questionnaire from the study at any time. The project was presented to the Regional Committee for Medical Research (Health Region East), which waived the need for ethical approval given the nature of the study (REK 2014/1425). The Norwegian Social Science Data Services approved the recording of data related to the study (2014/10220 - Oslo University Hospital)

\section{Consent for publication}

Not applicable.

\section{Availability of data and material}

The dataset used during the current study are available from the corresponding author on reasonable request.

\section{Competing interests}

The authors declare that they have no competing interests.

\section{Funding}

The work of this paper was funded by the ideal foundation: Norwegian Air Ambulance Foundation.

\section{Author's contributions}

PB initiated the project, wrote the protocol and led the project. SS and PB developed the questionnaire. PB did the data collection, analysis and first draft writing. SS, JR and Dø contributed in the analysis of data and the writing process as well as finalization of the paper. All authors approved the final version of the paper.

\section{Acknowledgements}

We would like to thank all members of crew and on call staff at the involved bases in Norway for participating. The study was funded by a research grant from Norwegian Air Ambulance Foundation. A special thank you to Dr. Emma Butterfield, LifeFlight Retrieval Medicine, for help with correcting and optimizing the language of the article.

\section{References}

1. Rasmussen K, Langdalen H, Sollid SJM, Abrahamsen EB, Sorskar LIK, Bondevik GT, Abrahamsen HB. Training and assessment of non-technical skills in Norwegian helicopter emergency services: a cross-sectional and longitudinal study. Scand J Trauma Resusc Emerg Med. 2019;27(1):1.

2. Goldshtein D, Krensky C, Doshi S, Perelman VS. In situ simulation and its effects on patient outcomes: a systematic review. BMJ Simulation Technology Enhanced Learning. 2020;6(1):3-9.

3. Msemo G, Massawe A, Mmbando D, Rusibamayila N, Manji K, Kidanto HL, Mwizamuholya D, Ringia P, Ersdal HL, Perlman J. Newborn mortality and fresh stillbirth rates in Tanzania after helping babies breathe training. Pediatrics. 2013;131(2):e353-60.

4. Sollid SJ, Bredmose PP, Nakstad AR, Sandberg M. A prospective survey of critical care procedures performed by physicians in helicopter emergency medical service: is clinical exposure enough to stay proficient? Scand J Trauma Resusc Emerg Med. 2015;23:45.

5. Abelsson A, Rystedt I, Suserud B-O, Lindwall L. Mapping the use of simulation in prehospital care - a literature review. Scand J Trauma Resusc Emerg Med. 2014;22(1):22. 
6. Bredmose PP, Habig K, Davies G, Grier G, Lockey DJ. Scenario based outdoor simulation in pre-hospital trauma care using a simple mannequin model. Scand J Trauma Resusc Emerg Med. 2010;18:13.

7. Glasheen J, Regan L, Richmond C, Edwards B, Burns B: On shift simulation in aeromedical operations - making it work. 2017 2017, 2(1).

8. Bredmose PP, Hagemo J, Røislien J, Østergaard D, Sollid S. In situ simulation training in helicopter emergency medical services: feasible for oncall crews? Adv Simul (Lond). 2020;5:7.

9. Helseforetakenes nasjonale luftambulansetjeneste ANS Årsrapport 2012 http://www.luftambulanse.no/system/files/internettvedlegg/arsrapport\%202012.pdf.

10. EuSim course description [https://eusim.org/courses/\#EuSim simulation instructor course].

11. Eppich W, Cheng A. Promoting Excellence and Reflective Learning in Simulation (PEARLS): development and rationale for a blended approach to health care simulation debriefing. Simul Healthc. 2015;10(2):106-15.

12. Hayes M. Experimental developement of the graphics rating method. Physiol Bull. 1921;18:98-9.

13. R Core Team. R: A Language and Environment for Statistical Computing. In., 3.11 edn. Vienna, Austria: R Foundation for Statistical Computing; 2013.

14. Hosny SG, Johnston MJ, Pucher PH, Erridge S, Darzi A. Barriers to the implementation and uptake of simulation-based training programs in general surgery: a multinational qualitative study. J Surg Res. 2017;220:419-26.e412.

15. Tariq U, Sood M, Goodsman D. The Facilitator's Role in London's Air Ambulance's simulation "moulage" training. Air Med J. 2015;34(2):92-7.

16. Spurr J, Gatward J, Joshi N, Carley SD. Top $10(+1)$ tips to get started with in situ simulation in emergency and critical care departments. Emerg Med J. 2016;33(7):514-6.

17. de Jonge LPJWM, Mesters I, Govaerts MJB, Timmerman AA, Muris JWM, Kramer AWM, van der Vleuten CPM. Supervisors' intention to observe clinical task performance: an exploratory study using the theory of planned behaviour during postgraduate medical training. BMC Med Educ. 2020;20(1):134.

\section{Figures}
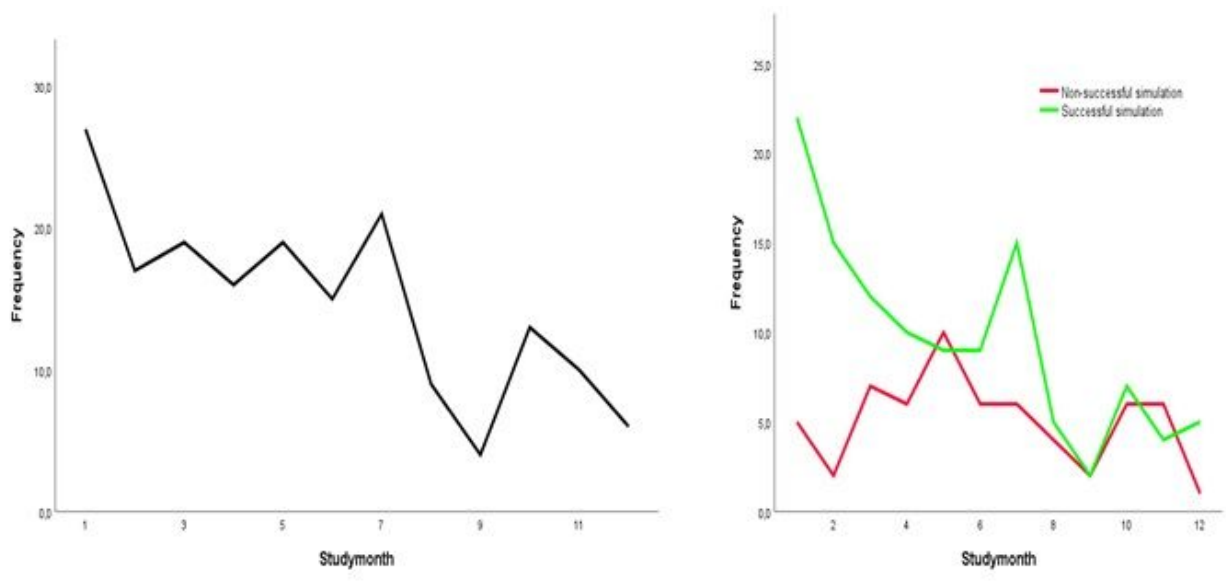

Figure 1

Figure 1a. Total number of monthly simulations at all bases during the study period. Figure 1b. Number of monthly successful simulations (gren line) and non-successful simulations (red line) during the study period. 

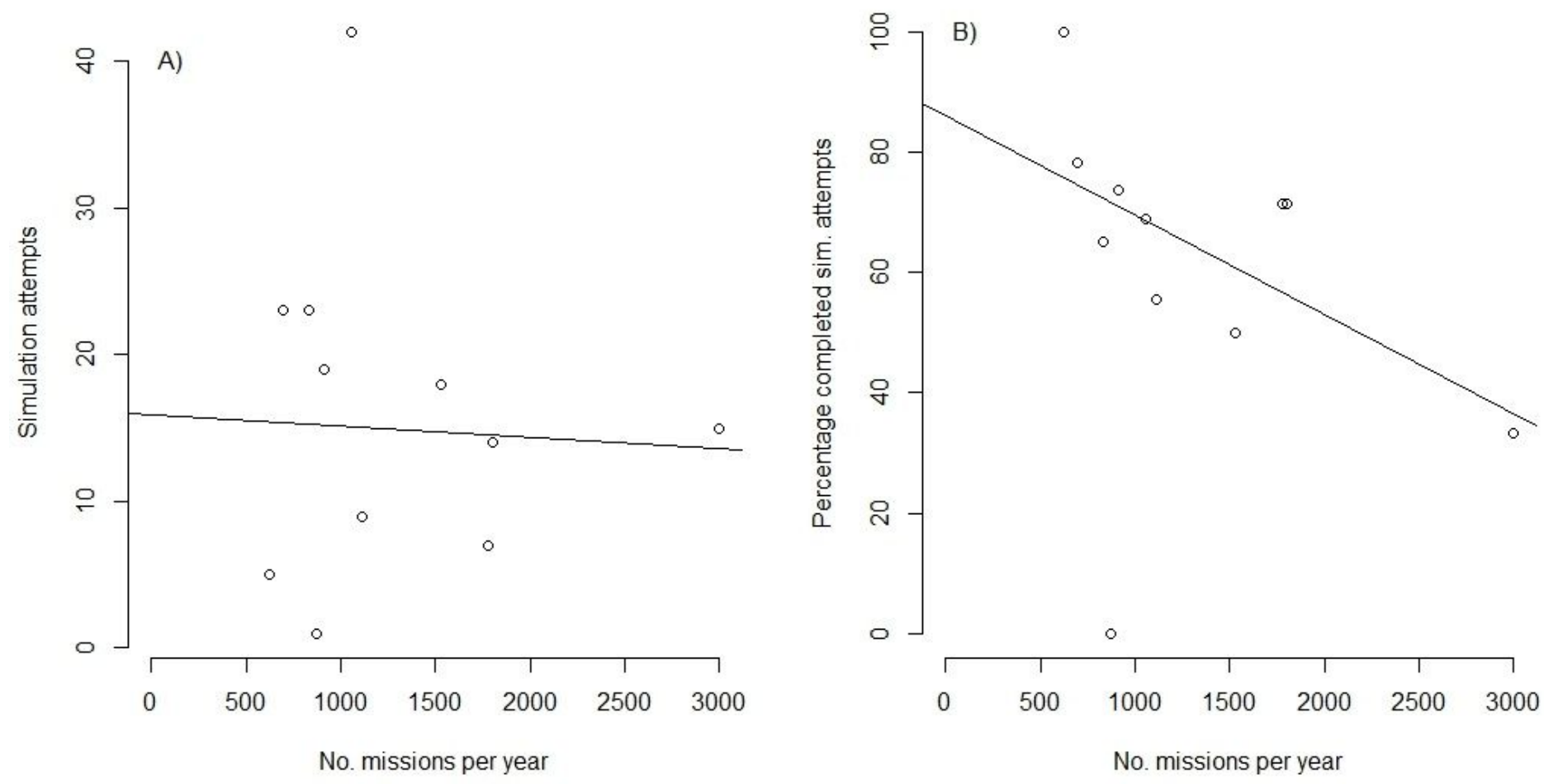

Figure 2

Figure 2a Association between number of missions at a base and attempted. Figure $2 \mathrm{~b}$ Association between number of missions at a base and completed simulations. Corresponding linear regression models superimposed. 